\title{
Isolation of a Xanthomonas oryzae pv. oryzae Flagellar Operon Region and Molecular Characterization of flhF
}

\author{
Yuwei Shen, Maw-shenq Chern, Francisco Goes Silva, and Pamela Ronald \\ Department of Plant Pathology, University of California-Davis, One Shields Avenue, Davis 95616, U.S.A. \\ Accepted 25 September 2000.
}

\begin{abstract}
An 8.1-kb DNA fragment from Xanthomonas oryzae pv. oryzae that contains six open reading frames (ORF) was cloned. The ORF encodes proteins similar to flagellar proteins FlhB, FlhA, FlhF, and FliA, plus two proteins of unknown function, ORF234 and ORF319, from Bacillus subtilis and other organisms. These ORF have a similar genomic organization to those of their homologs in other bacteria. The $f l h F$ gene product, FlhF, has a GTP-binding motif conserved in its homologs. Unlike its homologs, however, $X$. oryzae pv. oryzae FlhF carries two transmembrane-like domains. Insertional mutations of the $f$ lhF gene with the omega cassette or the kanamycin resistance gene significantly retard but do not abolish the motility of the bacteria. Complementation of the mutants with the wildtype $f l h F$ gene restored the motility. The $X$. oryzae pv. oryzae FlhF interacts with itself; the disease resistance gene product XA21; and a protein homologous to the PilL protein of Pseudomonas aeruginosa, XooPilL, in the yeast two-hybrid system. The biological relevance of these interactions remains to be determined.
\end{abstract}

Bacterial flagella are important virulence factors for pathogenesis of animals and plants (Finley and Falkow 1997; Moens and Vanderleyden 1996). In some plant-pathogen systems, flagella-driven chemotaxis plays a role in the early interactions with host plants (Vande Broek and Vanderleyden 1995). Motility enables foliar pathogens to reach internal sites in the leaves (Beattie and Lindow 1995). Recently, the bacterial protein flagellin has been found to be a plant elicitor, providing evidence that plants have a sensitive perception system for this protein (Felix et al. 1999).

Xanthomonas spp. bear a single polar flagellum and cause serious diseases to virtually all plant crops. $X$. oryzae pv. oryzae is the causal agent of rice bacterial blight, an important disease in the rice-growing areas of the world (Mew 1987). The bacteria infect rice leaves by entering hydathodes, multiplying in the epitheme, and accessing the xylem vessels (Mew et al. 1984). The transmission of the pathogen is favored by intense wind-driven rainfall that facilitates bacterial entry into

Corresponding author: P. Ronald; Telephone: +1-530-752-1654; Fax: +1-530-752-5674; e-mail: pcronald@ucdavis.edu

Nucleotide sequence and/or amino acid sequences of the flagellar operon region have been submitted to GenBank, accession no. AF226282. Sequence xoopilL also has been deposited in GenBank, accession no. AF226283. plant tissues through wounded leaf edges (Ou 1985). Feng and Guo showed that $X$. oryzae pv. oryzae chemotaxis occurs toward hydathode exudates of susceptible rice plants but not toward hydathode exudates of resistant plants (Feng and Guo 1975). This result suggests that chemotaxis plays a role in $X$. oryzae pv. oryzae pathogenicity before penetration of bacteria into the rice leaf. The flagellation and chemotactic properties of pathovars in the Xanthomonas spp., however, have not been extensively studied.

The pathogen-plant relationship in the $X$. oryzae pv. oryzaerice system follows a gene-for-gene pattern (Hopkins et al. 1992). Plants containing resistance genes are resistant to pathogens containing the corresponding avirulence genes. More than 20 resistance genes have been identified by genetic analysis, two of which, $X a 1$ and $X a 21$, have been cloned from rice (Song et al. 1995; Yoshimura et al. 1998). Two X. oryzae pv. oryzae avirulence genes, avrXa7 and avrXa10, and some virulence genes such as gumG, hrpX, xpsF, xpsD, hpal, and hpa2 also have been isolated (Dharmapuri and Sonti 1999; Kamdar et al. 1993; Ray et al. 2000; Tang et al. 1996; Zhu et al. 2000). Although significant progress has been made in the characterization of host and bacterial genes governing the interaction, little is known about the genes governing $X$. oryzae pv. oryzae flagellar biosynthesis and movement.

Bacterial flagella are complex structures. Their biosynthesis and locomotion require many genes (Macnab 1992). For example, the entire Salmonella typhimurium flagellar system requires at least 40 genes (Jones and Macnab 1990). Except for some of the receptor genes, the flagellar and related genes of S. typhimurium and Escherichia coli are found at a few chromosomal locations where they form contiguous clusters, namely, flagellar regions I, II, and III. Within each region, there are several operons that contain from one to as many as nine genes. These operons are arranged as a regulon (Macnab 1992; Manson et al. 1998). In contrast, the gram-positive bacterium, Bacillus subtilis, has a different organization of flagellar genes, although it is similar to S. typhimurium and $E$. coli in gene sequence and flagellar structure (Bischoff and Ordal 1992; Macnab 1992). B. subtilis has a large flagellar operon that contains at least 30 genes as well as several other smaller clusters (Bischoff and Ordal 1992). Some of the genes occur in the same order as their enteric counterparts, but in other cases the order is quite different. For instance, in $B$. sutilis, flagellar genes $f l h B$, flhA, and $f l h F$ are tandemly linked in the same operon. In $S$. typhimurium, however, following flhB and $f l h A$ is a chemotactic gene, flhE (Ditty et al. 1998; Macnab 1992). In contrast with the well-characterized flagella of 
mammalian pathogens, only a few flagellar genes have been cloned and characterized from phytopathogenic bacteria (Chesnokova et al. 1997; Pleier and Schmitt 1989).

In the present study, we isolated a flagellar operon region from $X$. oryzae pv. oryzae. The sequenced region contains six genes, among which a gene homologous to flh $F$ from $B$. subtilis was further characterized. Insertional mutations of $X$. oryzae pv. oryzae flhF retard but do not abolish bacterial motility. The mutants still produce normal flagella on swarm medium. X. oryzae pv. oryzae FlhF encoded by flhF interacts with XA21 and a $X$. oryzae pv. oryzae protein similar to PilL, a twitching motility protein from Pseudomonas aeruginosa, in the yeast two-hybrid system, which suggests that FlhF plays a role in other cell functions. FlhF also can interact with itself at the $\mathrm{C}$-terminal domain, suggesting that it may function as a dimer.

\section{RESULTS}

\section{Identification of $\mathrm{flhF}$ and isolation}

\section{of a flagellar gene region in $X$. oryzae pv. oryzae.}

In a yeast two-hybrid screen of a $X$. oryzae pv. oryzae (POX99A) genomic library, we used the XA21 kinase domain as bait in an attempt to isolate gene-encoding protein that interacts with the XA21 kinase domain. A 3.1-kb clone (pCX432) was isolated from five identical clones in two independent screens. The 3.1-kb fragment contains three ORF (Fig. 1). The first ORF, fused in frame to the gal4 activation domain of the pPC86 vector, encodes a protein homologous to a flagellar gene, $f l h F$, from other organisms such as $P$. putida and $B$. subtilis. The second ORF encodes a protein homologous to a protein of unknown function, and the third has high homology to another flagellar gene, fliA, the product of which is a sigma factor controlling the transcription of other flagellar genes (Ohnishi et al. 1990). The above results suggest that the $3.1-\mathrm{kb}$ fragment is a part of the flagellar operon in $X$. oryzae pv. oryzae.

Because flagella play important roles in bacterial pathogenicity, we isolated the flanking regions of $f l h F$ to better characterize the genes controlling flagella in $X$. oryzae pv. oryzae. To isolate a larger flagellar operon region, an $X$. oryzae pv. oryzae cosmid library was screened with a SalI fragment from $f l h F$. Five clones were found to contain the 3.1$\mathrm{kb}$ fragment. One of the clones, pHMX1, was selected for further study. A 5.5-kb EcoRI fragment and two BamHI fragments that were 4.4 and $10 \mathrm{~kb}$ from pHMX1 were subcloned into pUC18 and pBluescript, respectively. These three plasmids, pXO7, pBSB4.4, and pBSB10, were sequenced, as was $8.09 \mathrm{~kb}$ of the flagellar operon region. Sequence analysis showed that the flagellar operon region contains six ORF in the same orientation (Fig. 1). In addition to the three ORFencoding proteins, FlhF, ORF319, and FliA, there are three ORFs located upstream of $f l h F$. The two immediately upstream of $f l h F$ are homologous to $f l h A$ and $f l h B$, respectively. The ORF preceding $f l h B$ is ORF234, which encodes a protein homologous to a protein with unknown function from other organisms. These six ORFs are tandemly arranged, with some overlap between ORF234 and flhB and ORF319 and fliA, and a 588 base gap between $f l h A$ and $f l h F$. The organization of the five ORF downstream of ORF234 is basically the same as that in P. putida, B. subtilis, and Borrelia burgdoferi (Carpenter et al. 1992; Ge and Charon 1997). The identities of the deduced amino acid sequences of the five $X$. oryzae pv. oryzae genes range from 27.5 to $57.1 \%$ (Table 1). A BLAST search indi-

Table 1. Percent identity of Xanthomonas oryzae pv. oryzae flagellar proteins to homologs from selected organisms

\begin{tabular}{lccccc}
\hline Organism & FlhB $^{\mathbf{a}}$ & FlhA & FlhF & ORF 319 $^{\mathbf{b}}$ & FliA \\
\hline $\begin{array}{l}\text { Pseudomonas putida } \\
\text { Escherichia coli }\end{array}$ & $* \mathrm{c}$ & 43.7 & 34.5 & 57.1 & 50.8 \\
$\begin{array}{l}\text { Salmonella ty- } \\
\quad \begin{array}{l}\text { phimurium } \\
\text { Yersinia enteroco- }\end{array}\end{array}$ & 42.7 & 51.6 & $*$ & $*$ & 50.0 \\
$\quad$ litica & 40.1 & 50.3 & $*$ & $*$ & 48.0 \\
$\begin{array}{l}\text { Bacillus subtilis } \\
\text { Borrelia burgdorferi }\end{array}$ & 36.3 & 41.6 & 32.0 & 29.8 & $*$ \\
\hline
\end{tabular}

a Percents are relative to $100 \%$ of $X$. oryzae pv oryzae.

${ }^{\mathrm{b}} \mathrm{ORF}=$ open reading frame.

c $*=$ amino acid sequence not available.

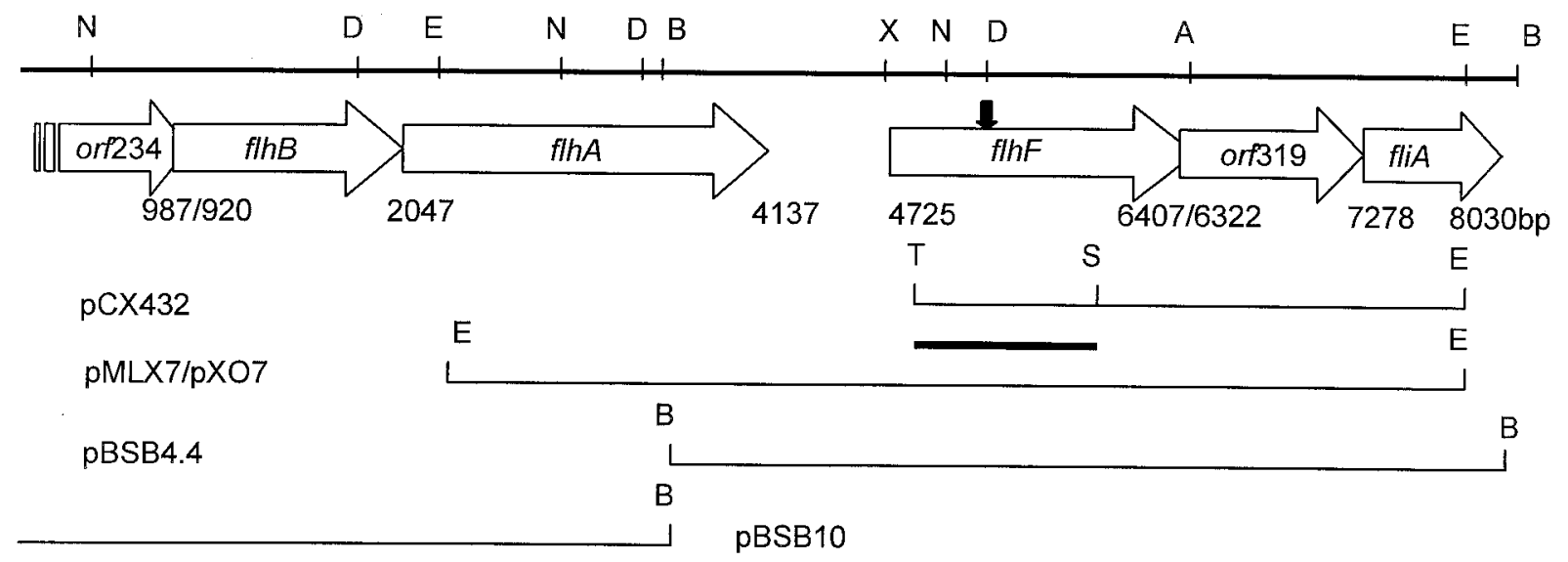

Fig. 1. Flagellar gene region of Xanthomonas oryzae pv. oryzae. Closed arrow $=$ site of the omega cassette $a^{2} \mathrm{Kan}^{\mathrm{R}}$ gene insertion for inactivation of the $f l h F$ gene. Plasmids pXO7, pBSB4.4, and pBSB10 are subclones of the $X$. oryzae pv. oryzae PXO99A cosmid clone pHMX1. pMLX7 contains the same 5.5-kb EcoRI fragment as in pXO7 and was used to complement flhF-deficient mutants. pCX432 was taken from a yeast two-hybrid screen with the XA21 kinase domain as bait. Thick line under pCX432 $=1-\mathrm{kb}$ DNA fragment used as a probe for Southern hybridization or cosmid library screen. $\mathrm{N}=$ NcoI; $\mathrm{D}=$ DraIII; E = EcoRI; $\mathrm{B}=$ BamHI; $\mathrm{X}=$ XhoI; A = ApaI; T = Tsp509I. 
cated that these flagellar genes are the first cloned from phytopathogenic bacteria.

\section{Analysis of interaction with the XA21 kinase domain and the structure of $X$. oryzae pv. oryzae FlhF.}

Because FlhF is fused in frame to the GAL4 activation domain, it is the protein that interacts with the XA21 kinase domain in a yeast two-hybrid system. In order to find which part of FlhF is involved in the interaction, fragments of flhF with a series of deletions on either side were used to test the interaction of their products with the XA21 kinase domain. It was found that only the full-length FlhF interacts with the XA21 kinase domain, whereas FlhF truncated on either end loses the ability to interact with the kinase domain (Fig. 2).

A putative ribosomal binding site was identified preceding the second ATG start codon, indicating that the FlhF protein translation likely starts from the second methionine. Consequently, the predicted protein is 561 amino acids (aa) in length with a predicted estimated molecular weight of $68 \mathrm{kDa}$. The deduced amino acid sequence contains a hydrophobic region from aa239 to aa256, which was predicted to be a transmembrane domain by the transmembrane regions and orientation program (TMpred) (Hofmann and Stoffel 1993). The total score of 1,026 is well above the threshold score of 500. There is another putative transmembrane helix from aa192 to aa214 that might be precluded by TMpred, probably as a result of a charged residue (R194). Protein motif analysis revealed motifs that are characteristic of the GTP-binding proteins GPTGAGKT, DTAG, and TKLD. The three consensus sequences of GTP-binding motifs are GXXXXGKS/T, DXXG, and NKXD (Carpenter et al. 1992). The first motif also is generally referred to as a P-loop (Saraste et al. 1990).

The existence of the GTP-binding motifs indicates that FlhF is likely to be a GTP-binding protein (Fig. 3). The deduced amino acid sequence of $X$. oryzae pv. oryzae flh $F$ was aligned with the known homologs from other organisms. The alignment revealed extensive identity in the $\mathrm{N}$ - and C-terminal regions, particularly the GTP-binding motif in the $\mathrm{C}$ terminus. The alignment also displayed dissimilarity between the $X$. oryzae pv. oryzae FlhF, and its homologs as the central portion (aa86 to aa341) of the X. oryzae pv. oryzae FlhF is not conserved. In addition, the predicted transmembrane domains of $X$. oryzae pv. oryzae FlhF could not be identified in its counterparts (Fig. 3).

\section{Insertional mutation of $f l h F$}

with antibiotic resistance cassettes.

To create a $f l h F$-deficient mutant, an omega cassette $\left(\mathrm{Sp}^{\mathrm{R}}\right.$ $\mathrm{Sm}^{\mathrm{R}}$ ) and a kanamycin resistance gene were used to create knockout mutants by inserting them into the unique DraIII site of flhF (Fig. 1). After electroporation, the revived cells were cultured on Kan or $\mathrm{Sp}-\mathrm{Sm}$ media to select recombinants resulted from either single- or double-crossover events. Recombination occurred at a high frequency $\left(2.4 \times 10^{-7}\right)$. Preliminary experiments showed that $X$. oryzae pv. oryzae is sensitive to ampicillin at a concentration of $100 \mu \mathrm{g}$ of ampicillin per milliliter. As a result, $120 \mathrm{Kan}^{\mathrm{R}}$ or $\mathrm{Sp}^{\mathrm{R}}-\mathrm{Sm}^{\mathrm{R}}$ colonies were transferred to ampicillin containing polysaccharide (PS) plates. Out of the $120 \mathrm{Kan}^{\mathrm{R}}$ or $\mathrm{Sp}^{\mathrm{R}}-\mathrm{Sm}^{\mathrm{R}}$ colonies, five and eight, respectively, did not grow on AMP plates, indicating that a double crossover had occurred and the vector DNA was eliminated from the chromosome. Southern analysis confirmed the replacement of wild-type $f l h F$ with the mutant $f l h F$. After insertion of the $1.2-\mathrm{kb} \mathrm{Kan}^{\mathrm{R}}$ cassette and the $2-\mathrm{kb}$ omega cassette, a 5.5-kb EcoRI fragment band in the wild-type PXO99A cells was shifted to 6.7 and $7.5 \mathrm{~kb}$, respectively (data not shown). One clone for each mutation was selected for further characterization.

\section{Phenotype analysis}

of $X$. oryzae pv. oryzae flhF-deficient mutants.

The flhF-deficient $X$. oryzae pv. oryzae mutants PXO99D $\Omega 2$ and PXO99DK7 were observed for their growth rate in comparison with the wild-type PXO99A cells. There was no difference in the growth rate between the mutants and the wild-type cells in PS liquid medium or on PS solid medium (data not shown). PXO99D $\Omega 2$ and PXO99DK7, together with wild-type PXO99A, were used to inoculate 6week-old rice plants of Xa21 containing IRBB21 and susceptible IR24 with a scissors-dipping method (Kauffman et al. 1973). Twelve days after inoculation, plants were scored by measuring lesion length. The mutants showed no difference in avirulence or virulence on resistant or susceptible rice varieties as compared with the controls (data not shown). Because the scissors-dipping method introduces wounds into the leaves, this procedure may allow $X$. oryzae pv. oryzae cells to bypass the hydathode and directly enter the xylem. A spray method was therefore also employed (Srivastava and Rao 1968). No significant difference in lesion length was ob-

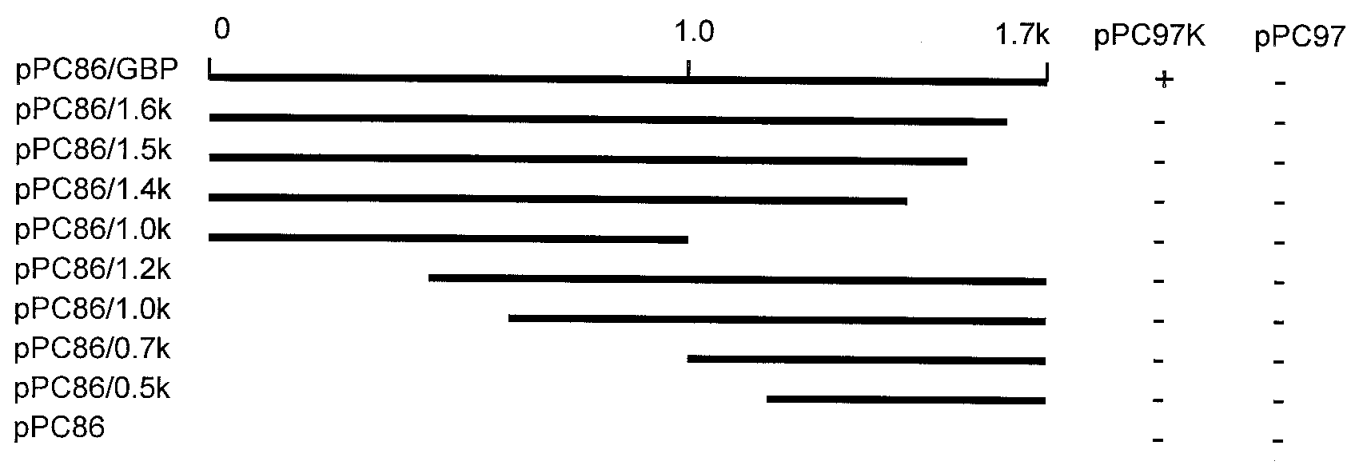

Fig. 2. Interaction between FlhF and the XA21 kinase domain. DNA fragment encoding the XA21 kinase and juxtamembrane domains was in frame ligated to gal4 binding domain of bait vector pPC97. Full-length $f l h F(\mathrm{GBP})$ and $f l h F$ fragments with different length truncations were in frame and ligated to the gal4 activation domain of pray vector pPC86. $+/-=$ positive or negative interaction on the basis of the expression of reporter genes LacZ and His3. 
served, however, between the wild type and mutant cells (data not shown). These results indicate that $f l h F$ does not encode a race-specific component, nor does it affect growth in medium or in planta.

Swarm plate analysis showed that cells of the wild-type and mutant $X$. oryzae pv. oryzae strains were motile on semisolid swarm medium (Sockett and Armitage 1991). The movement was very slow in the first day of culture, but got faster after 2 days (Fig. 4). This type of movement suggests that motility of $X$. oryzae pv. oryzae is inducible, which is seen in other Xan- thomonas pathovars (Kamoun and Kado 1990). Indeed, electron microscopy (EM) showed that cells of the wild-type and two mutant strains cultured on rich PS agar medium were not flagellated, whereas cells from swarm plates were flagellated (data not shown). Four days after inoculation, the motility zone of the wild-type and mutant cells was measured (Table 2). It was clear that the mutants were still motile, though the motility was severely impaired by the $f l h F$ mutation. The mutant PXO99D $\Omega 2$ carrying two transcription terminators in the $\Omega$ cassette swarmed slower than the mutant PXO99DK7.
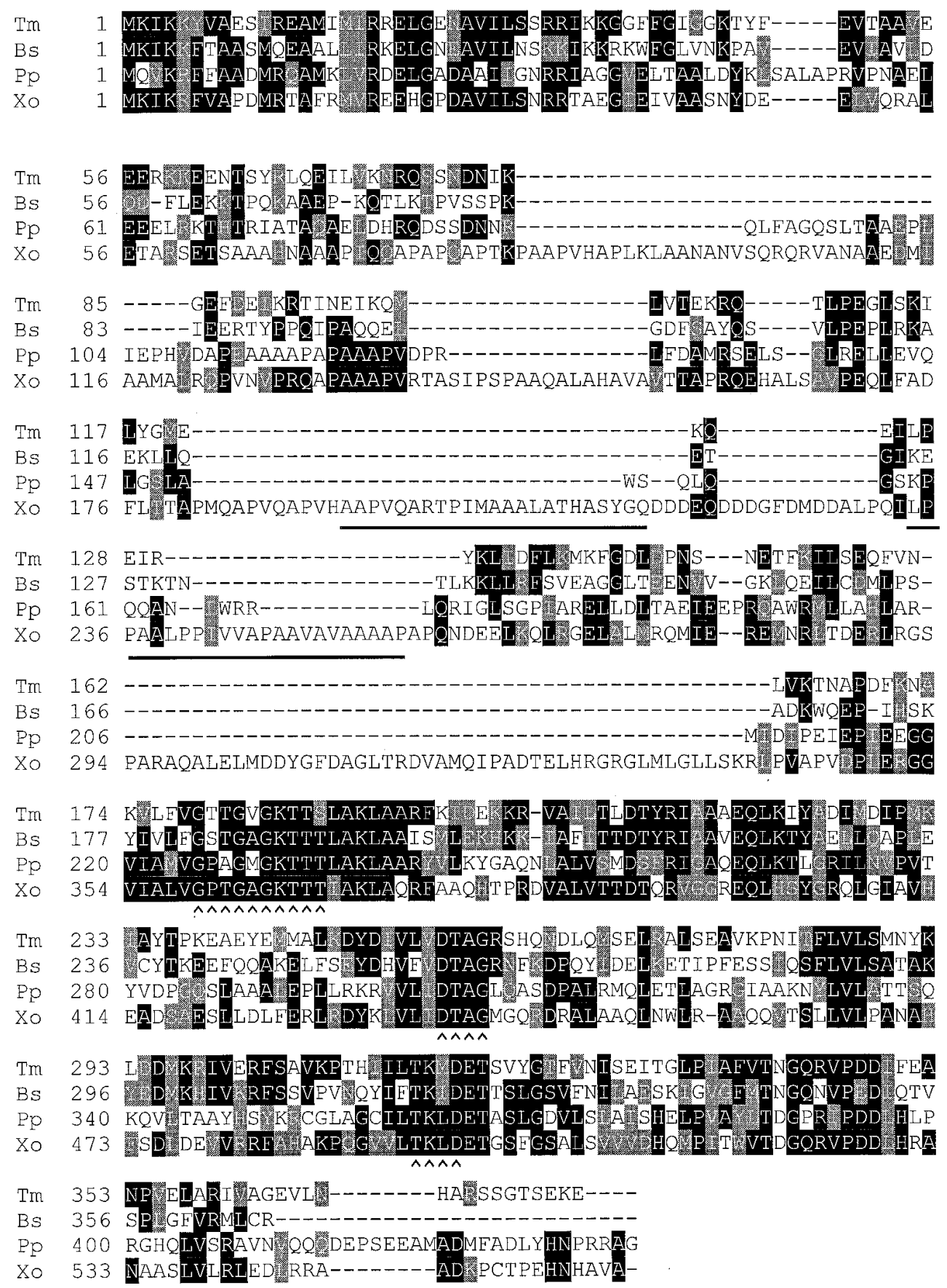

Fig. 3. Multiple alignment of FlhF amino acid sequences. Identical amino acids from all four organisms are shaded with black, whereas similar amino acids are hatched. Predicted transmembrane domains of Xanthomonas oryzae pv. oryzae FlhF are underlined with a thick line. Conserved GTP-binding motif is indicated with arrows. $\mathrm{Tm}=$ Thermotoga maritima $; \mathrm{Bs}=$ Bacillus subtilis; $\mathrm{Pp}=$ Pseudomonas putidas $;$ Xo $=X$. oryzae . 
This result suggests a polar effect on the expression of the downstream genes, although the effect was not severe enough to abolish motility. EM observation of the mutant cells did not show significant difference between the flagellar phenotype and the wild-type cells (data not shown). These results are distinct from the observation on the $f l h F$-null mutant of $B$. subtilis, which was nonmotile and nonflagellated (Carpenter et al. 1992).

To complement $f l h F$-deficient mutants, a wide-host-range plasmid, pMLX7, was introduced into PXO99D $\Omega 2$ and PXO99DK7 by conjugation. The pMLX7 plasmid contains a 5.5-kb EcoRI fragment that harbors flhF, ORF319, and a part of flhA and fliA. The complementation restored the mutants to their full motility (Table 2), indicating that $f l h F$ is a motilityassociated gene in $X$. oryzae pv. oryzae.

\section{FlhF interactor and FlhF function.}

From the above results it is clear that $f l h F$ plays a role in $X$. oryzae pv. oryzae motility. However, virtually nothing is known of its mode of function. To identify FlhF signaling components, $X$. oryzae pv. oryzae FlhF was used as bait to screen the $X$. oryzae pv. oryzae genomic library with a yeast two-hybrid system. In one screen, more than 20 clones were identified to encode parts of an FlhF-interacting protein. The full-length gene encoding the protein was isolated from a $X$. oryzae pv. oryzae cosmid clone. The deduced protein, XooPilL, is composed of 1,030 aa with a predicted molecular weight of $124 \mathrm{kDa}$ (Fig. 5). A BLAST search found that this protein is homologous to PilL encoded by the pilL gene from P. aeruginosa, with an overall identity of $29.8 \%$. Pill is composed of 836 aa and is thought to play a role in signal transduction of pilus-twitching motility (Mattick et al. 1996). The newly isolated XooPilL homolog has two transmembrane domains (aa209 to aa230 and aa876 to aa896), as predicted by TMpred, with a total score of 644 and 1,244, respectively. Furthermore, it was predicted to be an inner membrane protein by PSORT (a computer program for the prediction of protein localization sites in cells) and has a leucine-zipper motif with four leucine repeats (aa250 to aa271), which may be involved in protein-protein interaction. $P$. aerugonisa PilL, however, does not have a similar transmembrane domain yet does have a leucine-zipper motif with only three leucine repeats.

In the same screen, more than 20 clones contained parts of the $f l h F$ gene. These clones can be grouped according to the size of the $f l h F$ gene fragments inserted in the pray plasmid (Fig. 5). There are four groups of clones containing the $3^{\prime}$

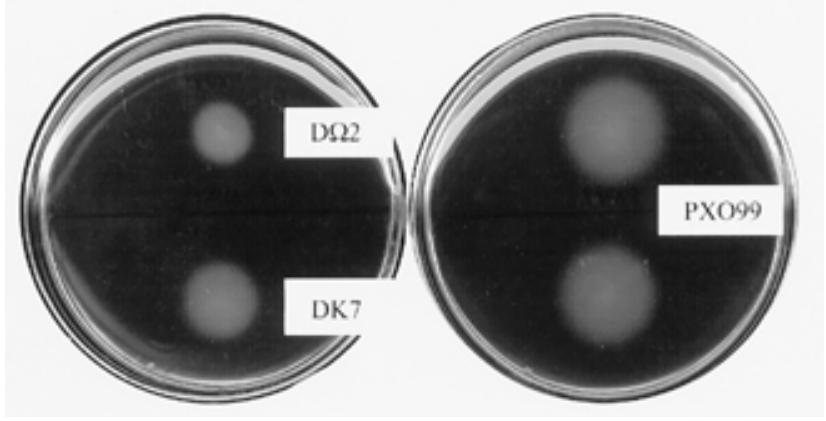

Fig. 4. Swarm plate analysis of PXO99D 22 and PXO99DK7 in comparison with wild-type PXO99A. Cells were grown on swarm plates at $28^{\circ} \mathrm{C}$ for 4 days. parts of $f l h F$, which are $1,567,1,347,1,089$, and 993 bp in length, respectively. The smallest fragment of $993 \mathrm{bp}$ still includes the GTP-binding motifs. This result suggests that the FlhF may form a dimer and that dimerization occurs in the Cterminal domain.

\section{DISCUSSION}

In an attempt to isolate XA21 kinase-interacting proteins from $X$. oryzae pv. oryzae, we cloned a $X$. oryzae pv. oryzae gene homologous to a flagellar gene, $f l h F$, from other organisms. An $8.1-\mathrm{kb} X$. oryzae pv. oryzae DNA fragment harboring the $f l h F$ homolog also was cloned and sequenced. Sequence analysis suggested that this region carries a flagellar operon region and encodes six ORF. To our knowledge, this is the first time such a flagellar operon region has been isolated from a phytopathogenic bacterium.

The six ORF in the 8.1-kb $X$. oryzae pv. oryzae DNA fragment designated ORF234, flhB, flhA, flhF, ORF319, and fliA are arranged in tandem in the same orientation (Fig. 1). All six ORF have homologs from other bacteria, but only the homologs of four ORF (flhB, flhA, FlhF, and FliA) have a role in flagellar biosynthesis (Carpenter et al. 1992; Macnab 1992; Ohnishi et al. 1990). The identity of the flagellar protein homologs ranges from 27.5 to $57.1 \%$ (Table 1). The four $X$. oryzae pv. oryzae ORF were named according to their homologs from other organisms. The function of ORF234 homologues is not yet known. The ORF319 homologue from B. subtilis encodes a putative $33-\mathrm{kDa}$ ATP-binding protein and was not required for either motility or chemotaxis (Kirsch et al. 1994). Instead, the ORF319 homolog is thought to be a flagellar biosynthesis switch protein (Kunst et al. 1997). The genomic organization of $X$. oryzae pv. oryzae genes is primarily the same as that of their counterparts in P. putida and $B$. subtilis (Carpenter et al. 1992; Ditty et al. 1998). There are some discrepancies, however, especially around fliA. In E. coli, fliA is in another flagellar region (Ge and Charon 1997). In $B$. subtilis, fliA has not yet been identified, although it is not in the position downstream of the ORF319 homolog ORF298, as it is in the case of $X$. oryzae pv. oryzae, because this position is filled by $c h e B$, a chemotexis gene. In addition, between $f l h B$ and the ORF234 homolog ORF219, there are three genes, fliP, fliQ, and fliR. In $P$. putida, flhA, flhF, orfC, and $f l i A$ are in the same order as their homologs in $X$. oryzae pv. oryzae, but genes upstream of flhA have not been identified. In $X$. oryzae pv. oryzae, there is a 587 base region with no ORF between $f l h A$ and $f l h F$. These results indicate a cer-

Table 2. Swarm plate analysis of Xanthomonas oryzae pv. oryzae strain PXO99A, its $f l h F$-deficient mutants PXO99D 22 and PXO99DK7, and mutants complemented with wild-type $f l h F^{\mathrm{a}}$

\begin{tabular}{lc}
\hline Strains & Diameter of motility zone $(\mathbf{c m})^{\mathbf{b}}$ \\
\hline PXO99A & $4.50 \pm 0.11$ \\
PXO99AC & $4.45 \pm 0.05$ \\
PXO99D 2 & $2.60 \pm 0.10$ \\
PXO99D $2 C^{c}$ & $3.75 \pm 0.25$ \\
PXO99DK7 & $2.85 \pm 0.15$ \\
PXO99DK7C $^{c}$ & $3.61 \pm 0.30$ \\
\hline
\end{tabular}

${ }^{\mathrm{a}}$ Cells were incubated at $28^{\circ} \mathrm{C}$ for 6 days.

${ }^{\mathrm{b}}$ Data $=$ mean \pm standard error of three replicates.

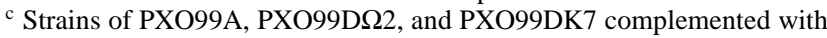
pMLX7 containing wild-type $f l h F$ gene. 
tain degree of evolutionary differences among these genera in flagellar gene organization.

$f l h F$ was further characterized among the six genes cloned from the $X$. oryzae pv. oryzae flagellar operon. flhF was first isolated from B. subtilis and later cloned from other organisms (Carpenter et al. 1992; Ditty et al. 1998; Ge and Charon 1997). It encodes a $41-\mathrm{kDa}$ putative GTP-binding protein (Carpenter et al. 1992), whereas the $f l h F$ isolated from $X$. oryzae pv. oryzae encodes a predicted $67-\mathrm{kDa}$ protein, which is bigger than its homologs from other organisms. Multiple alignment showed that the $\mathrm{N}$ - and $\mathrm{C}$-terminal regions of $X$. oryzae pv. oryzae FlhF are quite conserved in regard to its homologs, particularly in the GTP-binding motifs, which suggests that it also is a GTP-binding protein. The middle part of the protein, however, is much less conserved. For instance, TMpred predicted a hydrophobic region of 23 aa (aa234 to aa256), a putative transmembrane domain (Fig. 3). There may be another transmembrane helix situated at aa192 to aa214, probably precluded by TMpred as a result of a charged residue, $\mathrm{R}$ (198). The region between these two putative transmembrane helices has no positively charged residues, which is in line with the expected situation for a loop located outside the cytoplasm, according to the "positive-inside" rule (Wallin and von Heijne 1998). Both transmembrane helices and the loop are missing in the FlhF homologues. These results suggest that the $X$. oryzae pv. oryzae FlhF may be an innermembrane protein, whereas its homologs might be localized in the cytoplasm.

It has been suggested that FlhF plays a role in the flagellar biosynthesis in B. subtilis (Carpenter et al. 1992). A null mutation in $B$. subtilis flhF produced nonmotile cells lacking flagella, as determined by an agglutination test and Western blot analysis. Cells deficient in $f l h F$ failed to activate transcription of the hag and mot loci, encoding the flagellar filament structural protein flagellin and the motility protein, respectively (Carpenter et al. 1992). In contrast, although insertional mutations in $X$. oryzae pv. oryzae flhF did significantly retard motility of $X$. oryzae pv. oryzae and the omega cassette insertion resulted in an even more severe retardation, it did not abolish motility. We noticed that on swarm plates with $0.4 \%$ agar the cells of the wild-type and mutant strains move slower than those on swarm plates with $0.3 \%$ agar. Moreover, almost no movement was observed for the mutant PXO99D $\Omega$ grown on the swarm plates with $0.4 \%$ agar, displaying a more significant difference from the wild-type and mutant PXO99DK7 (data not shown). EM, however, showed that cells with insertional mutations in $f l h F$ still produce normal flagella (data not shown). It is possible that the mutant with the $\operatorname{Kan}^{\mathrm{R}}$ insertion in $f l h F$ had leaky expression, although the mutant with the omega cassette insertion carries a transcription terminator and should disrupt the $f l h F$ transcription and the downstream genes such as fliA, which regulates the transcription of the flagellar capping gene $f l h D$. Nonetheless, the normal flagellation of the mutant PXO99D $\Omega 2$ indicates that the $\Omega$ cassette did not exert a polar effect on fliA. The residual motility of the insertion mutants might be a result of a possible gene redundancy.

Because $X$. oryzae pv. oryzae FlhF interacts with the XA21 kinase domain in the yeast two-hybrid system, we initially postulated that FlhF might act as an avirulence or a virulence factor to trigger or disturb the XA21-mediated defense pathway, similar to the interaction of Yersinia spp. with its host, where Yop proteins can enter animal cells to destroy key functions of immune cells (Galan and Collmer 1999). An emerging theme in host-bacterial interactions is that virulence and accessory proteins that affect host-signal transduction are similar to domains of host proteins. For instance, Yersinia spp. YopM carries LRR domains commonly found in eukaryotic host proteins (Leug and Straley 1989). The FlhF protein has a P-loop motif, which is widely conserved in the largest class of plant resistance gene products (Baker et al. 1997). Our results by two methods from rice plant inoculations, with or without the Xa21 resistance gene with the mutants and wild-type PXO99A cells, did not support the above hypothesis. If the FlhF function was instrumental for bacteria virulence to rice plants, the susceptible rice plants, IR24, would show reduced lesion length when inoculated with FlhF mutants. Similarly, if FlhF conferred an avirulence function, increased lesion length would have been observed on Xa21 plants inoculated with the FlhF mutants. Such changes in lesion length were not observed (data not shown). Parallel experiments with $X$. oryzae pv. oryzae Korean race 1 (DY87031), which is normally virulent on the Xa21 line (Wang et al. 1998), and two mutants with the same insertional mutations in $f l h F$ also displayed no change in pathogenicity (data not shown).

In the present study, a protein homologous to $P$. aeruginosa PilL interacted with $X$. oryzae pv. oryzae FlhF. The PilL of $P$. aeruginosa is hypothesized to play a role in signal transduction of bacterial-twitching motility (Mattick et al. 1996). XooPilL, like FlhF, contains two predicted transmembrane domains, which suggests it is a membrane protein. Interestingly, analysis of the deduced protein sequence showed that it contains a leucine-zipper motif, which means it may interact with other proteins in a signal-transduction pathway. If XooPilL also plays a similar role in $X$. oryzae pv. oryzae, as it does in $P$. aeruginosa, XooPilL may have dual functions. In this scenario, XooPilL would control pili-twitching motility and flagella-driven motility. Such a dual function is reminis-

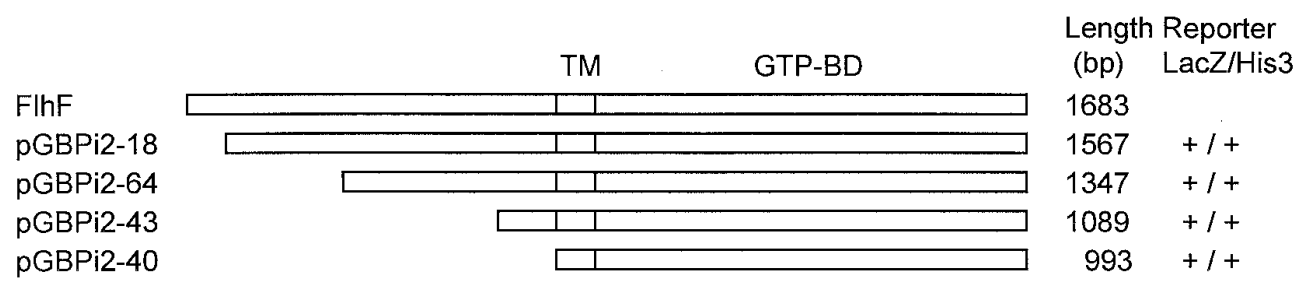

Fig. 5. Self-interaction of FlhF of Xanthomonas oryzae pv. oryzae in the yeast two-hybrid system. flhF is the full-length gene; pGBPi2-18, -64, -43, and -40 are representatives of the $X$. oryzae pv. oryzae clone groups that interact with FlhF and contain parts of $f l h F .+=$ expression of reporter genes LacZ and His3 for protein interaction. 
cent of the $E$. coli $\mathrm{FlhD}$, which functions as a positive regulator of the flagellar regulon and acts in other aspects of cell function, including cell division (Manson et al. 1998). Because many type IV pilus proteins have a remarkable similarity to chemotaxis proteins (Darzins and Russel 1997), it is possible that xoopilL is a new flagellar gene.

In the search for the $X$. oryzae pv. oryzae FlhF interactors, a series of clones that encodes parts of FlhF were isolated. The smallest clone is $993 \mathrm{bp}$, which encodes 331 aa of the Cterminal portion of the FlhF carrying the GTP-binding domain. This result suggests that the FlhF can interact with itself, forming a dimer. Further work is needed to characterize XooPilL and its relation to FlhF.

In summary, a flagellar operon region containing six genes was isolated from $X$. oryzae pv. oryzae. Among the six genes, four have homologs of known functions in flagellar biosynthesis from other organisms, whereas two have homologs of unknown function. $X$. oryzae pv. oryzae $f l h F$ is significantly different from its counterparts in other organisms in that it has two putative transmembrane domains. Mutations of $f l h F$ by insertional inactivation do not impair flagellation or affect race specificity, growth in media, or virulence on rice plants. The mutations, however, significantly decrease but do not abolish bacterial motility. The protein encoded by the $f l h F$ interacts with XooPilL, suggesting a possible role in signal transduction controlling bacterial motility. FlhF also interacted with itself. These results should open new avenues for the study of phytopathogenic bacteria flagella.

\section{MATERIALS AND METHODS}

\section{Bacterial strains and culture media.}

The bacterial strains and plasmids used in this study are described in Table 3 . X. oryzae pv. oryzae strains were routinely grown in liquid or solid PS media or NB medium (Difco, Detroit, MI, U.S.A) at $28^{\circ}$ C. E. coli strain DH10B (Gibco BRL, Grand Island, NY, U.S.A.), plasmids pUC19 (New England BioLabs, Beverly, MA, U.S.A.), and pBluescript (Stratagene, La Jolla, CA, U.S.A.) were used for all cloning experiments. E. coli cells were cultured in Luria-Bertani broth at $37^{\circ} \mathrm{C}$. The antibiotics used for $X$. oryzae pv. oryzae and E. coli were, per milliliter: $100 \mu \mathrm{g}$ of ampicillin, $50 \mu \mathrm{g}$ of gentamycin, $50 \mu \mathrm{g}$ of kanamycin, $50 \mu \mathrm{g}$ of spectinomycin, and $50 \mu \mathrm{g}$ of streptomycin, purchased from Sigma Chemical Co. (St. Louis, MO, U.S.A.).

\section{Molecular techniques.}

Standard recombinant DNA techniques were used (Sambrook et al. 1989). Restriction enzymes and ligase were obtained from New England BioLabs. DNA phosphatase (from shrimp) was obtained from Amersham Pharmacia Biotech Inc. (Piscataway, NJ, U.S.A.). X. oryzae pv. oryzae race 6 strain POX99A genomic DNA was prepared according to Wilson (1994). For Southern DNA hybridization, ${ }^{32} \mathrm{P}-\mathrm{dCTP}$ (New Life Science Products, Boston, MA, U.S.A.) was used to label DNA probes with a random labeling kit (Amersham Corp., Arlington Heights, IL, U.S.A.). A Midiprep kit (Qiagen, Chatsworth, CA, U.S.A.) was used to prepare large amounts of vector and plasmid DNA for sequencing. DNA sequencing on both strands of DNA fragments cloned in pBluescript or pPC86 was performed by the dideoxy-chain termination method with an automated sequencer (Model 400L; Li-Cor, Lincoln, NE, U.S.A.) (Sanger et al. 1977). M13 reverse and M13-20 primers were used to sequence the inserts in pBluescript. Primers GAL4TA (5'-GGATGTTTAATACCACT-3') and TADC1 (5'-TTGATTGGAGACTTGACC-3') were used to sequence the inserts in pPC86. To fill in gaps, a primer walking strategy was used with synthesized primers (Operon, Alameda, CA, U.S.A.). Polymerase chain reaction (PCR) was performed with Vent polymerase (New England Biolabs) and the Programmable Thermal Controller (MJ Research Inc., Watertown, MA, U.S.A.). PCR products were cloned with a TA cloning kit (Invitrogen Corp., Carlsbad, CA, U.S.A.). Bacterial transformation was done with the BRL Electroporator (Life Technologies Inc., Gaithersburg, MD, U.S.A.). DNA and protein sequence analyses and homolog searches were performed with Sequencher (Gene Codes, Ann Arbor, MI, U.S.A.), NCBI BLAST (Altschul et al. 1997), TMpred (Hofmann and Stoffel 1993), and CLUSTAL (Thompson et al. 1994).

\section{Identification of an $X$. oryzae pv. oryzae clone containing $f l h F$.}

The experiment was initially designed to search for interactors with the XA21 kinase domain. An Xa21 fragment that encodes the cytoplasmic kinase domain, including part of the juxtamembrane and C-terminal domains (Song et al. 1995), was generated with primers Pr822-29 (5'-AGGTCGACCCGGGAATGAAAGGCCACCCATT-3') and Pr822-20 (5'-GGGGTACCGGATCCTCAAAATTCAAGGCTCCCTTCAC-3').

The PCR product was cloned into the TA cloning vector PCR2.1. After the sequence was confirmed, the insert was released from PCR2.1 vector with SalI and BamHI and inserted into the binding domain vector pPC97 at the SalI-BglII site. The bait plasmid (pPC97K) was introduced into yeast cells of strain HF7c with the Li-Ac method, described in Clontech's yeast two-hybrid system manual (Clontech, Palo Alto, CA, U.S.A.).

To construct the library for the yeast two-hybrid screen, $X$. oryzae pv. oryzae chromosomal DNA from $X$. oryzae pv. oryzae race 6, strain PXO99, was partially digested with Tsp509I. Fragments ranging from 0.5 to $5 \mathrm{~kb}$ were inserted into the activation domain of pPC86 at the EcoRI site. The constructed library contains about $1 \times 10^{6}$ clones, with an average DNA insert size of approximately $2 \mathrm{~kb}$. The HF7c (pPC97K) cells were sequentially transformed with the $X$. oryzae pv. oryzae library and were spread on SD-Leu, -Trp, and - His media to select the kinase interactor. Out of $2.4 \times$ $10^{-7}$ transformants screened, $156 \mathrm{Leu}^{+}, \mathrm{Trp}^{+}$, and $\mathrm{His}^{+}$colonies were tested for the expression of another reporter gene, LacZ. The $\mathrm{His}^{+}$and $\mathrm{LacZ}^{+}$colonies were further verified. The prey plasmids were isolated from the $\mathrm{His}^{+}$and $\mathrm{LacZ}^{+}$colonies, amplified in DH10B, and returned to the HF7c (pPC97K) cells to check interaction between the kinase and interactor proteins. The verified positive clones were sequenced. One of the clones, pCX432, encodes a protein homologous to a flagellar protein FlhF from other bacteria (Fig. 1).

\section{Isolation of a flagellar gene region.}

To isolate the flagellar gene region, a 1-kb SalI fragment from pCX432 that contains part of $f l h F$ was used to screen a cosmid library of $X$. oryzae pv. oryzae (race 2, strain POX86) 
that was constructed with cosmid vector pHM1 (Fig. 1). The positive clones were confirmed by Southern hybridization. One confirmed clone was subcloned into pBluescript or pUC18 with BamHI or EcoRI. The subclones containing the flanking regions of pCX432 were sequenced (Fig. 1).

\section{Analysis of the interacting part of FlhF with the XA21 kinase domain and construction of $f l h F$-deficient mutants.}

To find which part of FlhF is essential for interaction with the XA21 kinase domain, $f l h F$ fragments with truncations of different lengths were constructed by PCR amplification with pXO7 as template. The fragments were fused in frame with the gal4 activation domain. The constructed plasmids were used for transformation of yeast $\mathrm{HF} 7 \mathrm{c}$ cells containing pPC97K or pPC97 (Fig. 2). The interaction test was performed as described above.

A 4.4-kb BamHI-EcoRI DNA fragment from pXO7 harboring the $f l h F$ gene was subcloned into the pUC18 plasmid at the BamHI-EcoRI site. The resultant plasmid, PUCX4.4, was linearized in a DraIII site internal to $f l h F$ (Fig. 1). The linearized plasmid DNA was blunt ended by filling it with Klenow enzyme. An omega cassette (Prentki and Krisch 1984) containing a streptomycin-spectomycin resistance gene and a kanamycin resistance gene were inserted into the $f \mathrm{~h} F$ region at the DraIII site, described below.

The omega cassette was released from plasmid $\mathrm{pHP} 45 \Omega$ (Prentki and Krisch 1984) with BamHI. The protruding 5' end was filled with T4 DNA polymerase. The omega cassette was then ligated to the linearized pUCX4.4. Because of the presence of a transcription terminator at both ends of the cassette, the insertional mutation with the omega cassette was deemed to cause a polar effect on the transcription of downstream genes in the operon. Therefore, a terminatorless kanamycin resistance gene cassette was used for the insertional inactivation of $f l h F$. A 1.28-kb $\mathrm{Kan}^{\mathrm{R}}$ fragment was released from pUC4K (Amersham Pharmacia Biotech) with BamHI blunt ended as described above and ligated into pUCX4.4 at the DraIII site. The orientation of the $f l h F$ and $\operatorname{Kan}^{\mathrm{R}}$ cassette was determined by restriction digestion with $\mathrm{XhoI}$, which cuts at a site upstream of $f l h F$ and into the $\mathrm{Kan}^{\mathrm{R}}$ gene. Only the clones containing $\mathrm{Kan}^{\mathrm{R}}$ that are oriented in the same direction as $f l h F$ were chosen to transform the wild-type PXO99A cells.

The constructed plasmids pUCXDK and pUCXD $\Omega$ with insertion of $\mathrm{Kan}^{\mathrm{R}}$ and omega cassettes in $\mathrm{flh} F$ were introduced into PXO99A cells by electroporation. The PXO99A cells were freshly cultured on PS agar plates and single colonies were used to inoculate PS liquid medium. The cells were cultured overnight to an optical density of about 0.6 at $600 \mathrm{~nm}$ and washed with cold-wash buffer ( $10 \%$ glycerol in water) three times. Approximately $100 \mathrm{ng}$ of pUCXDK and pUCXD $\Omega$ DNA was used for electroporation of $20 \mu \mathrm{l}$ of the PXO99A competent cells, five electroporations for each plasmid construct. Electroporation was done at $2.0 \mathrm{kv}, 4 \mathrm{~K} \Omega, 330$ $\mu \mathrm{F}$. After electroporation, the cells were pooled and revived in $5 \mathrm{ml}$ of SOC medium for $6 \mathrm{~h}$. The cells were plated onto PS agar plates containing either kanamycin or spectromycinstreptomycin. After 3 days of culture, a number of the colonies were transferred onto PS agar plates containing KanAmp or Spe-Sm-Amp to select recombinants with doublecrossover events. To confirm the replacement of the wild-type $f l h F$ with the insertional mutant gene by allelic exchange, a Southern analysis of the EcoRI-digested genomic DNA from the wild-type cell and the mutants was carried out with a 1-kb SalI fragment from pCX432 as probe.

Table 3. Bacterial strains and plasmids used in the study

\begin{tabular}{|c|c|c|}
\hline Strains or plasmids & Description & Source or reference \\
\hline \multicolumn{3}{|l|}{ Escherichia coli } \\
\hline DH10B & & Gibco BRL, Grand Island, NY, U.S.A. \\
\hline S17-1 & 294, recA, chromosomally integrated $\mathrm{RP} 4$ derivative, $\mathrm{Sm}^{\mathrm{R}}, \mathrm{Tc}^{\mathrm{R}}$ & Simon et al. 1983 \\
\hline \multicolumn{3}{|c|}{ Xanthomonas oryzae pv. oryzae } \\
\hline PXO99A & Philippine race 6 strain; avirulent to rice plants with Xa21 & Hopkins et al. 1992 \\
\hline $\mathrm{PXO} 99 \mathrm{D} \Omega 2$ & $\mathrm{flhF}^{-} \mathrm{Kan}^{\mathrm{R}}$ gene inserted at DraIII site of flhF & This study \\
\hline PXO99DK7 & $\mathrm{flhF}^{-} \Omega$ cassette $\left(\mathrm{Sm}^{\mathrm{R}}-\mathrm{Sp}^{\mathrm{R}}\right)$ inserted at DraIII site of $\mathrm{flhF}$ & This study \\
\hline $\mathrm{PXO} 99 \mathrm{D} \Omega 2 \mathrm{c}$ & PXO99D $\Omega 2$ complemented with pMLX7 & This study \\
\hline PXO99DK7c & PXO99DK7 complemented with pMLX7 & This study \\
\hline \multicolumn{3}{|l|}{ Plasmids or cosmids } \\
\hline pPC97 & GAL4, DNA-BD, Leu2, Amp ${ }^{R}$ & Chevray and Nathans 1992 \\
\hline pPC86 & GAL4, DNA-AD, Trp1, Amp ${ }^{R}$ & Chevray and Nathans 1992 \\
\hline pBDleu & GAL4, DNA-BD, Leu2, Amp ${ }^{R}$ & Gibco BRL \\
\hline pPC97K & pPC97 with XA21 kinase fusion & This study \\
\hline pCX432 & pBC 86 with $3.1-\mathrm{kb} X$. oryzae pv. oryzae clone & This study \\
\hline pBDLeu3.1 & pBDleu with 3.1-kb SmaI-SpeI fragment from pCX432 & This study \\
\hline pUC18 & OripUC, $\mathrm{Amp}^{\mathrm{R}}$ & BioLabs, Beverly, MA, U.S.A. \\
\hline pML122 & OriV, OriT, Mob/rep, $\mathrm{Gm}^{\mathrm{R}}, \mathrm{Nm}^{\mathrm{R}}$ & Labes et al. 1990 \\
\hline pBluescript SK & OriColE1, Amp ${ }^{\mathrm{R}}$ & Stratagene, La Jolla, CA, U.S.A. \\
\hline pUC4K & OripBR322, $\mathrm{Amp}^{\mathrm{R}}$, containing $\mathrm{Kan}^{\mathrm{R}}$ cassette & Pharmacia, Piscataway, NJ, U.S.A. \\
\hline $\mathrm{pHP} 45 \Omega$ & pUC 18 containing $\Omega$ cassette $\mathrm{Sp}^{\mathrm{R}}-\mathrm{Sm}^{\mathrm{R}}$ & Prentki and Krisch 1984 \\
\hline pHMX1 & pHM1 X. oryzae pv. oryzae cosmid clone & This study \\
\hline pXO7 & pUC18 with $5.5-\mathrm{kb}$ EcoRI fragment from pHMX1 & This study \\
\hline pMLX7 & pML122 with5.5-kb EcoRI fragment & This study \\
\hline pUCX4.4 & pUC18 with 4.4-kb BamHI-EcoRI fragment from pXO7 & This study \\
\hline $\operatorname{pUCXD} \Omega 2$ & pUCX4.4 with $\Omega$ insertion at $\operatorname{DraIII}$ & This study \\
\hline pUCXDK7 & pUCX 4.4 with $\mathrm{Kan}^{\mathrm{R}}$ insertion at DraIII & This study \\
\hline pBSB4.4 & pBluescript with 4.4-kb BamHI fragment from pHMX1 & This study \\
\hline pBSB10 & pBluescript with $10-\mathrm{kb}$ BamHI fragment from pHMX1 & This study \\
\hline
\end{tabular}




\section{Complementation of $\boldsymbol{f l h} \boldsymbol{F}$-deficient mutants.}

A 5.5-kb EcoRI fragment from $X$. oryzae pv. oryzae cosmid clone pHMX1 containing $f l h F$ was subcloned into the wildhost-range vector pML122 in the EcoRI site (Fig. 1). The orientation of the insert was checked to ensure that the insert was in the same direction as the $n p t$ promoter. The resultant plasmid pMLX7 was introduced into E. coli strain S-17 by electroporation. The pMLX7 was transferred to the two $f l h F$ deficient mutants, PXO99D $\Omega 2$ and PXO99DK7, by biparental mating (Hopkins et al. 1992). The transconjugants were then used for phenotype analysis.

\section{Motility analysis.}

Fresh colonies from PS agar plates were stabbed into swarm plates composed of $0.03 \%$ (wt/vol) Bacto Peptone, $0.03 \%$ yeast extract, and $0.3 \%$ agar. The inoculated cells were cultured for 4 days or longer at $28^{\circ} \mathrm{C}$ and examined for bacteria swarming away from the inoculated site (Sockett and Armitage 1991).

\section{Identification of FlhF interactors.}

A 3.1-SmaI-SpeI fragment from pCX432 was ligated in frame into pBDleu (Gibco BRL) at the SmaI-SpeI site. $f l h F$ in the $3.1-\mathrm{kb}$ fragment was fused in frame to the gal4 binding domain. This bait plasmid was transformed into the yeast strain HF7c. The transformation and $X$. oryzae pv. oryzae library screen were done as indicated above.

\section{ACKNOWLEDGMENTS}

We thank J. Leach for providing the cosmid library of $X$. oryzae pv. oryzae strain PXO86; A. Püler for providing plasmid pLM122; C. Kado, A. Lopez, D. Chen, and P. Sharma for valuable discussions during the study; and G. Young and E.-M. Lai for reading the manuscript. This work was funded by the NIH (GM55962). Y. Shen was supported by a Rockefeller Foundation Postdoctoral Fellowship.

\section{LITERATURE CITED}

Altschul, S. F., Alejandro, A. S., Zhang, J., Zhang, Z., Miller, W., and Lipman, D. J. 1997. Gapped BLAST and PSI-BLAST: A new generation of protein database search programs. Nucleic Acids Res. 25:3389-3402.

Baker, B., Zambryski, P., Staskawicz, B., and Dinesh-Kumar, S. P. 1997. Signaling in plant-microbe interaction. Science 276:726-733.

Beattie, G. A., and Lindow, S. E. 1995. The secret life of foliar bacterial pathogens on leaves. Annu. Rev. Phytopathol. 33:145-172.

Bischoff, D. S., and Ordal, G. W. 1992. Bacillus subtilis chemotaxis: A deviation from the Escherichia coli paradigm. Mol. Microbiol. 6:2328.

Carpenter, P. B., Hanlon, D. W., and Ordal, G. W. 1992. flhF, a Bacillus subtilis flagellar gene that encodes a putative GTP-binding protein. Mol. Microbiol. 6:2705-2713.

Chesnokova, O., Coutinho, J. B., Khan, I. H., Mikhail, M. S., and Kado, C. 1997. Characterization of flagella genes of Agrobacterium tumefaciens, and the effect of a bald strain on virulence. Mol. Microbiol. 23:579-590.

Chevray, P. M., and Nathans, D. 1992. Protein interaction cloning in yeast: Identification of mammalian proteins that react with the leucine zipper of jun. Proc. Natl. Acad. Sci. USA 89:5789-5793.

Darzins, A., and Russel, M. A. 1997. Molecular genetic analysis of type4 pilus biogenesis and twitching motility using Pseudomonas aeruginosa as a model system: A review. Gene 192:109-115.

Dharmapuri, S., and Sonti, R. V. 1999. A transposon insertion in the gumG homologue of Xanthomonas oryzae pv. oryzae causes loss of extracellular polysaccharide production and virulence. FEMS Microbiol. Lett. 179:53-59.
Ditty, J. L., Grimm, A. C., and Harwood, C. S. 1998. Identification of a chemotaxis gene region from Pseudomonas putida. FEMS Microbiol. Lett. 159:267-273.

Felix, G., Dwan, J. D., Volko, S., and Boller, T. 1999. Plants have a sensitive perception system for the most conserved domain of bacterial flagellin. Plant J. 18:265-276.

Feng, T. Y., and Guo, T. T. 1975. Bacterial leaf blight of rice plant. VI. Chemotactic response of Xanthomonas oryzae pv. oryzae to water droplets exudated form water pores on the leaf of rice plants. Bot. Bull. Acad. Sin. (Taipei) 16:126-136.

Finley, B. B., and Falkow, S. 1997. Common themes in microbial pathogenicity revisited. Microbiol. Mol. Biol. Rev. 61:136-169.

Galan, J. E., and Collmer, A. 1999. Type III secretion machines: Bacterial devices for protein delivery into host cells. Science 284:13221328.

Ge, Y., and Charon, N. W. 1997. Identification of a large motility operon in Borrelia burgdorferi by semi-random PCR chromosome walking. Gene 189:195-201.

Hofmann, K., and Stoffel, W. 1993. TMbase: A database of membrane spanning proteins segments. Biol. Chem. Hoppe-Seyler 347:166.

Hopkins, C. M., White, F. F., Choi, S. H., Guo, A., and Leach, J. E. 1992. Identification of a family of avirulence gene from Xanthomonas oryzae pv. oryzae. Mol. Plant-Microbe Interact. 5:451-459.

Jones, C. J., and Macnab, R. M. 1990. Flagellar assembly in Salmonella typhimurium: Analysis with temperature-sensitive mutants. J. Bacteriol. 172:1327-1339.

Kamdar, H. V., Kamoun, S., and Kado, C. I. 1993. Restoration of pathogenicity of avirulent Xanthomonas oryzae pv. oryzae and $X$. campestris pathovars by reciprocal complementation with $h r p X o$ and $h r p X c$ genes and identification of $H r p X$ function by sequence analysis. J. Bacteriol. 175:2017-2025.

Kamoun, S., and Kado, C. I. 1990. Phenotype switching affecting chemotaxis, xanthan production, and virulence in Xanthomonas campestris. Appl. Environ. Microbiol. 56:3855-3860.

Kauffman, H. E., Reddy, A. P. K., Hsieh, S. P. V., and Marca, S. D. 1973. An improved technique for evaluation of resistance of rice varieties to Xanthomonas oryzae. Plant Dis. Rep. 57:537-541.

Kirsch, M. L., Carpenter, P. B., and Rodal, G. W. 1994. A putative ATPbinding protein from the chelfla locus of Bacillus subtilis. DNA (NY) 4:271-275.

Kunst, F., Ogasawara, N., Moszer, I., Albertini, A. M., Alloni, G., Azevedo, V., Bertero. M. G., and Bessier, P. 1997. The complete genomic sequence of the gram-positive bacterium Bacillus subtilis. Nature 390:249-256.

Labes, M., Puler, A., and Simon, R. 1990. A new family of RSF1010derived expression and lac-fusion broad-host-range vectors for Gramnegative bacteria. Gene 8:37-46.

Leug, K. Y., and Straley, S. L. 1989. The yopM gene of Yersinia pestis encodes a released protein having homology with the human platelet surface protein GPIb alpha. J. Bacteriol. 171:4623-4632.

Macnab, R. M. 1992. Genetics and biogenesis of bacterial flagella. Annu. Rev. Genet. 26:131-158.

Manson, M. D., Armitage, J. P., Hoch, J. A., and Macnab, R. M. 1998. Bacterial locomotive and signal transduction. J. Bacteriol. 180:10091022.

Mattick, J. S., Whitchurch, C. B., and Alm, R. A. 1996. The molecular genetics of type-4 fimbriae in Pseudomonas aeruginosa: A review. Gene 179:147-155.

Mew, T. W. 1987. Current status and future prospects of research on bacterial blight of rice. Annu. Rev. Phytopathol. 25:359-382.

Mew, T. W., I-pin, C., and Huang, J. S. 1984. Scanning electron microscopy of virulent and avirulent strains of Xanthomonas campestris $\mathrm{pv}$. oryzae on rice leaves. Phytopathology 74:635-641.

Moens, S., and Vanderleyden, J. 1996. Functions of bacterial flagella. Crit. Rev. Microbiol. 22:67-100.

Ohnishi, K., Kutsukake, K., Suzuki, H., and Iino, T. 1990. Gene fliA encodes an alternative sigma factor specific for flagellar operons in Salmonella typhimurium. Mol. Gen. Genet. 221:139-147.

Ou, S. H. 1985. Bacterial leaf blight. Pages 70-74 in: Rice Diseases. Commonwealth Microbiological Institute, Cambrian News, Aberystwyth, U.K.

Pleier, E., and Schmitt, R. 1989. Identification and sequence analysis of two related flagellin genes in Rhizobium meliloti. J. Bacteriol. 171:1467-1475. 
Prentki, P., and Krisch, H. M. 1984. In vitro insertional mutagenesis with a selectable DNA fragment. Gene 29:303-313.

Ray, S. K., Rajeshwari, R., and Sonti, R. V. 2000. Mutants of Xanthomonas oryzae pv. oryzae deficient in general secretory pathway are virulence deficient and unable to secrete xylanase. Mol. PlantMicrobe Interact. 13:394-401.

Sambrook, J., Fritsch, E. F., and Maniatis, T. 1989. Molecular Cloning: A Laboratory Manual. 2nd ed. Cold Spring Harbor Laboratory, Cold Spring Harbor, NY, U.S.A.

Sanger, F., Nicklen, S., and Coulson, A. R. 1977. DNA sequencing with chain-terminating inhibitors. Proc. Natl. Acad. Sci. USA 74:5463-5467.

Saraste, M., Sibbald, P. R., and Wittinghofer, A. 1990. The P-loop: A common motif in ATP- and GTP-binding proteins. Trends Biochem. Sci. 15:430-434.

Simon, R., Priefer, V., and Puhler, A. 1983. A broad host range mobilization system for in vitro genetic engineering: Transposon mutagenesis in Gram negative bacteria. Biotechnology 1:784-790.

Sockett, R. E., and Armitage, J. P. 1991. Isolation, characterization, and complementation of a paralyzed flagellar mutant of Rhofobacter sphaeroceles WS8. J. Bacteriol. 173:2786-2790.

Song, W. Y., Wang, G. L., Chen, L. L., Kim, H. S., Pi, L. Y., Holston, T., Gardner, J., Wang, B., Zhai, W. X., Zhu, L. H., Fauguet, C., and Ronald, P. 1995. A receptor kinase-like protein encoded by the rice disease resistance gene, Xa21. Science 270:1804-1806.

Srivastava, D. N., and Rao, Y. P. 1968. Epidemiology and prevention of bacterial blight disease of rice in India. Int. Rice Comm. Newsl. 17:27-33.

Tang, J.-L., Feng, J.-X., Li, Q.-Q., Wen, H.-X., Zhou, D.-L., Wilson, T. J. G., Dow, J. M., Ma, Q.-S., and Daniels, M. J. 1996. Cloning and char- acterization of the $r p f C$ gene of Xanthomonas oryzae pv. oryzae: Involvement in exopolysaccharide production and virulence to rice. Mol. Plant-Microbe Interact. 9:664-666.

Thompson, J. D., Higgins, D. G., and Gibson, T. J. 1994. CLUSTAL W: Improving the sensitivity of progressive multiple sequence alignment through sequence weighting, positions-specific gap penalties and weight matrix choice. Nucleic Acids Res. 22:4673-4680.

Vande Broek, A., and Vanderleyden, J. 1995. The role of bacterial motility, chemotaxis, and attachment in bacteria-plant interactions. Mol. Plant-Microbe Interact. 8:800-810.

Wallin, E., and von Heijne, G. 1998. Genome-wide analysis of integral membrane proteins from eubacterial, archaean, and eukaryotic organisms. Protein Sci. 7:1029-1038.

Wang, G., Ruan, D., Song, W., Sideris, S., Chen. L., Pi, L., Zhang, S., Zhang, Z., Fauguet, C., Gaut, B. S., Whalen, M., and Ronald, P. C. 1998. Xa21D encodes a receptor-like molecule with a leucine-rich repeat domain that determines race-specific recognition and is subject to adaptive evolution. Plant Cell 10:765-779.

Wilson, K. 1994. Preparation of genomic DNA from bacteria. Pages 2.4.1-2.4.5 in: Current Protocols in Molecular Biology. F. M. Ausubel, R. Brent, R. E. Kingston, D. D. Moore, J. G. Seidman, J. A. Smith, and K. Struhl, eds. John Wiley \& Sons Inc., New York.

Yoshimura, S., Yamanouchi, U., Katayose, Y., Toki, S., Wang, Z. X., Kono, I., Kurata, N., Yano, M., Iwata, N., and Sasaki, T. 1998. Expression of $\mathrm{Xa1}$, a bacterial blight-resistance gene in rice, is induced by bacterial inoculation. Proc. Natl. Acad. Sci. USA 95:1663-1668.

Zhu, W., Magbanua, M. M., and White, F. F. 2000. Identification of two novel $h r p$-associated genes in the $h r p$ gene cluster of Xanthomonas oryzae pv. oryzae. J. Bacteriol. 182:1844-1852. 